\title{
ANTROPOLOGIA SOCIAL E CIÊNCIAS FORENSES
}

\author{
SOCIAL ANTHROPOLOGY AND FORENSIC SCIENCES
}

\section{ANTROPOLOGÍA SOCIAL Y CIENCIAS FORENSES}

Rebecca Lemos Igreja
Doutora em Antropologia
Universidade de Brasília,
Brasil
Maria Teresa Sierra Camacho
Doutora em Sociologia
Centro de Investigaciones y Estudios Superiores en Antropología Social,
México
Simone Rodrigues
Doutora em Ciência Política
Universidade de Brasília,
Brasil
Talita Rampin
Doutora em Direito
Universidade de Brasília,
Brasil
Eniversidade Federal de Goiás,
Brasil

\section{Resumo}

Editorial do segundo número, terceiro volume, da revista “Abya Yala -Revista sobre acesso à justiça e direitos nas Américas".

Palavras-chave: Antropologia Social, Ciências Forenses, México. 


\title{
Resumen
}

Editorial del segundo número del tercer volumen, de la revista “Abya Yala -Revista sobre acceso a la justicia y derechos en las Américas".

Palabras clave: Antropología Social, Ciencias Forenses, México.

\begin{abstract}
Editorial of the second issue of the third volume, of the magazine "Abya Yala -Journal on access to justice and rights in the Americas".
\end{abstract}

Keywords: Social Anthropology, Forensic science. México 
$\mathrm{N}$ esta edição da Revista "AbyaYala -Revista sobre acesso à justiça e direitos nas Américas" trazemos a discussão original proposta por Carolina Robledo Silvestre e Rosalva Aída Hernández Castillo sobre a relação entre as ciências forenses e a antropologia social. Como explicam as organizadoras do dossiê na introdução, o objetivo é propor uma reflexão sobre os desafios e as possibilidades de se construir pontes epistêmicas e políticas entre as duas disciplinas, tendo como ponto de partida as suas experiências de pesquisa colaborativa com familiares de desaparecidos e desaparecidas no México. Essas pesquisas são desenvolvidas no âmbito do Grupo de Investigaciones en Antropología Social y forense (GIASF).

Para introduzir um pouco mais, $\mathrm{O}$ GIASF é constituído por uma equipe de cientistas sociais que se juntaram pela necessidade de compreender o fenômeno da violência, especialmente da desaparição de pessoas, no contexto atual mexicano (http://www.giasf.org/quieacutenes-

somos.html). Como as organizadoras do dossiê e demais autores e autoras demonstram, o México passa por momentos difíceis de violência vinculada, de maneira especial, a alta incidência do crime organizado e do narcotráfico. No entanto, essa violência é potencializada, e mesmo incrementada, com a atuação das forças de controle do Estado, especialmente, a resultante da militarização da segurança pública. Sob a justificativa da guerra contra o narcotráfico, violências extremas despontam, como torturas, mortes e desaparecimentos, que ocorrem cotidianamente e que atingem a vários cidadãos mexicanos e, de maneira, especial, a população indígena.

Como consta em sua apresentação, o Grupo buscou desenvolver uma metodologia de pesquisa colaborativa, em conjunto com organizações civis e familiares das pessoas desaparecidas, a partir da perspectiva antropológica e forense. Seu interesse principal está em desenvolver conhecimentos científicos socialmente relevantes sobre os contextos do desaparecimento forçado, através do reconhecimento da dimensão sociocultural da violência, da elaboração de pareceres de especialistas independentes e da contribuição metodológica para a construção da memória coletiva. A equipe promove a formação de uma comunidade científica em torno desse fenômeno e a troca de conhecimentos com parentes de pessoas desaparecidas e membros de organizações civis, valorizando sua expertise e capacidade técnica. Também acompanha 
esses atores no desenvolvimento de estratégias para a busca e identificação de pessoas desaparecidas e a compreensão abrangente do fenômeno do desaparecimento forçado de pessoas.

Essa poderia ser apenas uma apresentação do grupo em seu site de internet. No entanto, quem acompanha o trabalho dos pesquisadores e pesquisadoras que o integram, como Carolina Robledo Silvestre e Rosalva Aída Hernández Castillo, organizadoras desse número, reconhece a dimensão e o valor do trabalho empírico que o grupo vem realizando e os enormes desafios que enfrentam. O tema em si já demonstra as dificuldades que afrontam. Como estudar a violência? Como analisá-la? Que metodologia? Que perspectiva? Como incorporar a muldimensionalidade dos fatores que a geram ou a justificam? Como dar conta dos diferentes atores e atores que se envolvem, sejan como provocadores ou vítimas dessa violência? Como encontrar soluções, saídas, para fenômenos tão imponderáveis e tão graves para a sociedade como um todo? O tema é desafiante não somente em termos científicos, mas também porque seu estudo pode colocar os próprios pesquisadores e pesquisadoras em situações de risco, transformando-os em possíveis vítimas do fenômeno que analisam. Pode-se agregar os desafios pessoais que enfrentam de conviver e analisar situações tão dolorosas como o sofrimento das famílias que são acompanhadas na busca dos desaparecidos, e com elas, desenvolver estratégias de resistência e de busca de apoio e solução.

O dossiê apresentado ainda nos oferece uma entrevista instigante realizada por Sandra Odeth Gerardo Pérez e por Paola Alejandra Ramírez González com o Dr. Francisco Ferrándiz, antropólogo social e pesquisador vinculado ao Instituto de Lengua, Literatura y Antropología (ILLA) do Centro de Humanidades y Ciencias Sociales (CCHS) no Consejo Nacional de Investigación (CSIC) da Espanha. O Dr. Ferrándiz narra sua experiência com o acompanhamento dos processos de exumações das fossas comuns da Guerra Civil Espanhola, que ocorrem já há dez anos. Esse acompanhamento faz parte de seu projeto de pesquisa "Las políticas de la memoria en la España contemporánea: el caso de la guerra civil". As organizadoras da entrevista solicitaram ao Doutor que contribuísse com a reflexão sobre a construção da memória histórica em relação às repercussões sociais da recuperação dos corpos, sobre os diálogos e desafios interdisciplinares entre antropologia social e ciências forenses e, finalmente, sobre as contribuições que a antropologia pode dar à construção da verdade e na busca de justiça. 
Por fim, contamos com a resenha de Sandra Odeth Gerardo Pérez sobre o livro Necropolitics: Mass Graves and Exhumations in the Age of Human Rights, organizado, igualmente, pelo Dr. Francisco Ferrándiz e por Antonius C. G. M. Robben. O livro foi publicado em 2017, pela University of Pennsylvania Press e faz parte da série Pennsylvania Studies in Human Rights. Como nos explica Sandra, o livro reúne oito artigos que expõem a diversidade de contextos políticos e socioculturais nos quais exumações foram realizadas em um período histórico que se inicia após a Segunda Guerra Mundial.

A revista Abya-Yala, uma revista que se comprometeu em dar espaço para as diversas experiências latino-americanas de busca e de promoção de acesso à justiça, regozija-se por poder publicar esse dossiê que nos aporta tantas análises originais e profundas sobre um problema que atinge o continente como um todo, e porque não dizer, o mundo como um todo. Regozija-se que pesquisadoras como Carolina e Rosalva Aída se juntem a nós nessa publicação, reconhecendo a notoriedade como especialistas que possuem nesse campo.

Esse novo número da nossa revista Abya-Yala corresponde ao esforço que realizamos para produzir uma revista acadêmica internacional que traga novos conhecimentos, novos dados, novas pesquisas, novas formas de fazer ciência e de se comunicar com a sociedade.

pesquisas, novas formas de fazer ciência e de se comunicar com a sociedade. 